\title{
Dual-foraging and co-ordinated provisioning in a tropical Procellariiform, the wedge-tailed shearwater
}

\author{
Bradley C. Congdon*, Andrew K. Krockenberger, Brian V. Smithers \\ School of Tropical Biology, James Cook University, PO Box 6811, Cairns, Queensland 4870, Australia
}

\begin{abstract}
To sustain breeding while simultaneously compensating for poor local resource availability, many temperate Procellariiformes (tube-nosed seabirds) access highly productive areas 'atdistance' from breeding colonies using a unique dual-foraging strategy. We tested for, and observed, a similar dual foraging strategy in a tropical Procellariiform, the wedge-tailed shearwater Puffinus pacificus. Foraging adults repeatedly performed short-trip cycles of multiple 1 to $4 \mathrm{~d}$ trips followed by a single long-trip of $\sim 8 \mathrm{~d}$. As with temperate species, wedge-tailed shearwaters used long-trips to build body reserves that they passed onto chicks by not self-provisioning adequately during the early stages of each short-trip cycle. Unlike temperate species (1) long-trip length and adult mass change during long-trips was inversely related to adult mass at the beginning of the same long-trip, and (2) foraging mode changeover appeared to be co-ordinated and was not initiated by adults reaching some critical lower mass. This implies that the dual-foraging pattern observed in wedge-tailed shearwaters is a consequence of the median time adults require to replenish body reserves on long-trips. We conclude that foraging strategies in wedge-tailed shearwaters vary spatially relative to nearcolony resource availability, and that dual-foraging is a general Procellariiform life-history strategy used to address similar ecological constraints in both temperate and tropical systems. Our findings suggest that wedge-tailed shearwaters of the southern Great Barrier Reef (GBR) may be dependent on localised areas of high productivity 'at-distance' from breeding colonies to sustain breeding.
\end{abstract}

KEY WORDS: Dual-foraging $\cdot$ Co-ordinated provisioning $\cdot$ Feeding ecology $\cdot$ Wedge-tailed shearwater · Puffinus pacificus $\cdot$ Procellariiform · Great Barrier Reef

\section{INTRODUCTION}

Recent studies show that many adult temperate Procellariiform (tube-nosed) seabirds cannot simultaneously replenish both their own body reserves and maintain chick development using near-colony zones of low productivity (e.g. Chaurand \& Weimerskirch 1994, Granadeiro et al. 1998, Weimerskirch 1998, Weimerskirch \& Cherel 1998). Temperate Procellariiformes overcome these limitations by adopting a unique dual or bimodal foraging strategy that alternates multiple short foraging trips in resource-poor, near-colony waters with longer trips to highly productive areas 'at-distance'. During near-colony trips, adults assimilate little food and so sacrifice body condition to satisfy chick requirements (Weimerskirch 1998, Weimerskirch \& Cherel 1998). At some critical mass they perform an extended trip to regain body condition before returning to continue chick provisioning. For many Southern Hemisphere Procellariiformes, distant foraging areas have been identified as upwelling zones of the Antarctic convergence over $2000 \mathrm{~km}$ from breeding colonies (e.g. Klomp \& Schultz 2000, Waugh et al. 2000). In some species dual-foraging is facultative. At colonies where, or in years when, near-colony resources are sufficient, adults provision based on local productivity alone (Granadeiro et al. 1998, Waugh et al. 2000). Such variations in strategy imply 
that dual-foraging can be unambiguously linked to the use of distant highly productive foraging areas in these species.

Tropical Procellariiformes face similar energetic constraints, yet it is unlikely that they consistently access the same highly productive temperate waters to compensate for poor local resource availability. This is particularly true of the smaller pan-tropically distributed Procellariiform species, such as the wedge-tailed shearwater Puffinus pacificus. How then do tropical species replenish their own reserves while simultaneously satisfying chick requirements? Two possibilities exist. Firstly, tropical Procellariiformes may use a dualforaging strategy similar to temperate species to access currently unknown, highly productive but more localised foraging zones in the tropics. Limited evidence for this possibility exists. Phoebastria immutabilis (Laysan albatross) and P. nigripes (black-footed albatross) nesting in the subtropics at Tern Island, French Frigate Shoals, Hawaii, both have bimodal foraging trip durations similar to temperate Procellariiformes (Fernandez et al. 2001, Hyrenbach et al. 2002). However, the generality of this finding to other tropical Procellariiformes is questionable. It has been suggested that although Laysan and black-footed albatross nest on tropical islands they are not tropical species. This is because they access temperate waters from the Hawaiian Islands while breeding, and forage solely in temperate and polar waters outside breeding periods (Hyrenbach et al. 2002).

Alternatively, unlike temperate species, tropical Procellariiformes may consistently obtain sufficient food from near-colony waters. If so, either the near-colony resources available per chick must be greater in the tropics, or the energy requirements of tropical chicks and/or adults must be significantly lower. The former is at odds with the long held belief that pelagic tropical systems are consistently resource-poor environments for pelagic foraging seabirds (Ashmole 1971), but some support for this model exists. Unlike Laysan and blackfooted albatross, wedge-tailed shearwaters, nesting on Tern Island, French Frigate Shoals, Hawaii, do not use a dual-foraging strategy. Adults provide for both themselves and chicks using highly productive near-shore waters (Baduini 2002). However, it is possible that deep water upwelling adjacent to Tern Island generates prey productivity and predictability not typical of pelagic tropical systems (Baduini 2002), which also casts doubt on the generality of this result.

Controversy also exists over the possible mechanisms controlling adult provisioning behaviour in Procellariiformes. An important conclusion of temperate studies of Puffinus tenuirostris (short-tailed shearwaters) and $P$. griseus (sooty shearwaters) has been that patterns of chick provisioning and adult foraging in mated pairs are independent and driven by adults preferentially maintaining their own body mass, rather than by chick condition or endogenous rhythms (Weimerskirch 1998, Weimerskirch \& Cherel 1998). In contrast, chick condition rather than adult body mass has been identified as an important determinant of provisioning rates in wedge-tailed shearwaters and other Procellariiform species under both unimodal and bimodal foraging strategies (e.g. Hamer \& Thompson 1997, Hamer et al. 1999, Weimerskirch et al. 2000, Baduini 2002). Currently the link between foraging strategy and the relative importance of chick versus adult condition in determining provisioning rates remains unclear.

We examined foraging behaviour of wedge-tailed shearwaters in the southern Great Barrier Reef (GBR), Australia, at a mid-shelf colony not known to have closely associated areas of high productivity. We aimed to determine whether intra-specific variation in foraging strategy occurs relative to the Hawaiian population and so test whether subtropical Procellariiformes consistently provision both themselves and chicks using a unimodal foraging strategy. By doing so, we also aim to establish the potential for wedge-tailed shearwater breeding success on the GBR to be dependent on localised areas of high productivity 'at-distance' from breeding colonies. We also aim to distinguish between adult body mass and chick condition as the principal determinants of variation in adult foraging and provisioning behaviour, as well as establish the proximate mechanism for any changes in foraging mode observed among mated pairs at this tropical/subtropical location.

\section{MATERIALS AND METHODS}

This study was undertaken during February 2001 at Heron Island $\left(23^{\circ} 26^{\prime} \mathrm{S}, 151^{\circ} 51^{\prime} \mathrm{E}\right)$, a coral cay of the Southern GBR, Australia, that straddles the Tropic of Capricorn. A total of 16 nest burrows were monitored. Adult provisioning rate, chick growth and chick survivorship were monitored at each nest daily. Chicks were weighed twice a day at 06:00 and 16:00 h using an electronic balance $( \pm 0.1 \mathrm{~g})$. Between these times no adult visits or chick feeding were observed. Culmen and tarsus measurements were also obtained for each chick every $4 \mathrm{~d}$ using dial callipers $( \pm 0.1 \mathrm{~mm})$. At each burrow, both adults were banded for individual recognition and attendance was monitored continuously from 17:00 to 05:00 h daily. During monitoring burrow entrances were partially obstructed with markers that allowed adult visits to be detected. After adults had entered the burrow and initial chick feeding was complete (as indicated by chicks no longer begging) the visiting adult was captured, identified and weighed 
using a Pesola spring balance $( \pm 0.5 \mathrm{~g})$. Chick weights were also obtained immediately following any known adult visit to a nest. After each adult capture, adults were returned to the burrow and markers reset so that subsequent visits by other adults could be detected. During burrow inspections, birds resting on the surface within a $10 \mathrm{~m}$ radius of each target burrow were checked for bands. Adult foraging trip length was defined as the time (d) between consecutive observations of an individual at a nest. Occasionally, adults could not be identified because they escaped prior to capture (mean nest ${ }^{-1}=0.11, \mathrm{SE}=0.013, \mathrm{n}=\sim 18$ observations nest ${ }^{-1}$ ). For analysis of attendance, 1 adult from that nest was randomly allocated to each missing value.

Adult foraging patterns. Adult foraging patterns were first examined using a frequency distribution of foraging trip duration (as per Waugh et al. 2000, Baduini 2002). This frequency distribution was tested for deviation from both a Poisson and Normal distribution using Kolmogorov-Smirnov goodness-of-fit. However, as a single $8 \mathrm{~d}$ trip is equivalent to eight $1 \mathrm{~d}$ trips in total foraging time, plotting foraging trip duration simply as a frequency distribution overstates the importance of shorter trips. In addition, individual adults that undertake more short-trips will be statistically over represented. We removed this bias by establishing the time spent (as a proportion of days) in foraging trips of different length for each individual and then took the mean across individuals, thereby using individuals rather than trips as units of replication. To test for differences among the proportion of time spent on foraging trips of different duration we performed a Kruskal-Wallis ANOVA. When significant, we further tested for bimodality of foraging trip length using posthoc pair-wise Mann-Whitney tests among trip length categories (with Bonferroni correction). All analyses were undertaken with SPSS for Windows 11.0 (2001, SPSS).

Adult mass change. Foraging trip length could be defined as either long or short, with a single long-trip always being followed by a series of 3 to 6 short-trips comprising a short-trip cycle (see 'Results'). Relative differences in per day mass changes for individual adults during long- and short-trips were compared via pair-wise analysis of 16 individuals for which complete long-trips were obtained. Partial short-trips only were obtained for these individuals. The same 16 individuals were also used in regression analyses examining relationships between long-trip length and adult mass at the beginning and end of long-trips. A separate set of 16 individuals for which complete short-trip cycles were obtained was used to establish an independent measure of adult mass changes during complete shorttrip cycles. This second group of individuals was also used in regression analyses examining relationships between short-trip length and adult mass at the beginning and end of short-trip cycles.

It was not possible to determine if feeding was always complete at the time chick begging stopped and adult weight measurements were taken. Consequently, an unknown number of the adult weight measurements may have contained partial food loads. To minimise this potential source of variation in comparative analyses, all adult weights were standardised to pre-feeding values. This was done by adding any increase in chick weight observed between 16:00 $\mathrm{h}$ and the time of an adult visit to the adult mass obtained during the same visit. This means that adult weights used in each analysis always include the entire food load returned to the colony from the previous days foraging. Consequently, observed changes in adult mass could result from actual changes in adult body reserves or variations in food loads between observations.

To test whether adult mass change was associated with changes in food loads rather than adult reserves, further independent analyses of the variation in chick meal sizes were undertaken. The relative meal size associated with a specific adult visit was calculated as the difference between consecutive 16:00 h chick weight measurements. Effectively, this measurement provided an estimate of the food assimilated by a chick during the $24 \mathrm{~h}$ period following each feed. ANCOVA was then used to test for consistent variation in meal size (food loads) with particular foraging trip parameters. Individual chicks were used as factors in these ANCOVA.

Chick condition and provisioning rates. Chick condition prior to a specific feeding event was established by first regressing chick mass against chick size, using tarsus length as a measure of size. Chick condition on the day in question was then defined as the residual of body mass divided by the mass value predicted from the tarsus-mass relationship (as per Baduini 2002). To determine if adult provisioning responded to chick condition, change in chick mass (food assimilated) was regressed against chick condition $24 \mathrm{~h}$ prior to the mass measurement in an ANCOVA that used individual chicks as factors. This analysis included the control nests where adults were not handled.

Co-ordinated switching of adult foraging modes. To test for co-ordinated switching in adult foraging behaviour between mated pairs, we determined the period of time (d) between when 1 adult started a longtrip and its mate ended its closest temporally associated long-trip. These data comprised 24 observations with potential long-trip changeover differences ranging between -3 and $+3 \mathrm{~d}$. The observed distribution described by these data was then tested against the 
distribution expected if long-trip changeovers occurred randomly relative to each other. The expected distribution was generated using a resampling algorithm that generated 100 sets of 24 random integers between -3 and +3 and determined the mean frequency at which each value occurred. The similarity between the observed and expected distributions was tested using likelihood ratio $\chi^{2}$ goodness-of-fit.

\section{RESULTS}

\section{Adult foraging pattern}

The frequency distribution of adult feeding trip duration (Fig. 1a) was significantly different from both a Poisson (Kolmogorov-Smirnov $Z=3.95$, p $<0.001$, $\mathrm{n}=243$ ) and Normal distribution (KolmogorovSmirnov $Z=5.99, \mathrm{p}<0.001, \mathrm{n}=243$ ). The mean proportion of time spent on foraging trips of different durations also varied (Kruskal-Wallis $\chi_{9}^{2}=150.6, \mathrm{p}<$ 0.001). A greater proportion of time was spent on $1 \mathrm{~d}$ trips than on trips of any other duration (Fig. 1b). Significantly more time was also spent on 2, 3 and $8 \mathrm{~d}$ trips than on 5 and $6 \mathrm{~d}$ trips and on $8 \mathrm{~d}$ trips than on
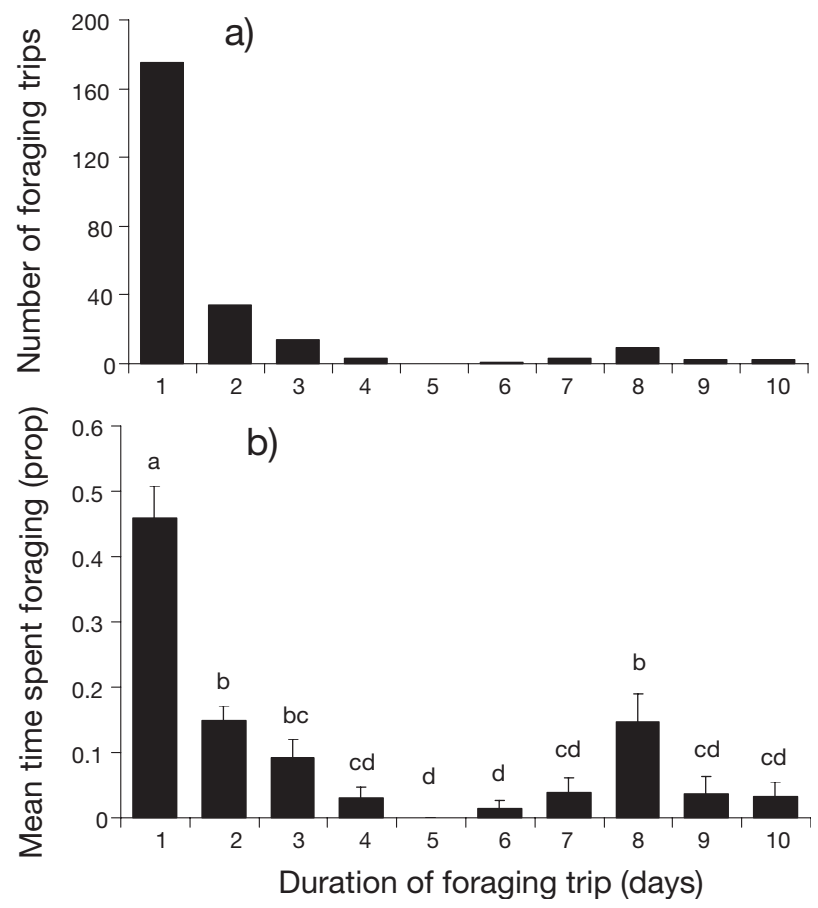

Fig. 1. Puffinus pacificus. (a) Distribution of foraging trip durations on Heron Island, GBR, 2001. (b) Mean (+ SE, $\mathrm{n}=32$ ) proportion of time spent in each foraging trip duration by individual adults on Heron Island, GBR, 2001. Different letters indicate means that are significantly different (Mann-Whitney pairwise comparison with Bonferroni correction). Prop: proportion all trips over $3 \mathrm{~d}$ (Fig. 1b). This pattern of differences unambiguously defines a bimodal distribution in the mean proportion of time adults spend on foraging trips of different duration (Fig. 1b). In general, adults make a single long-trip of between 6 and $10 \mathrm{~d}$ (mean $=8.06 \mathrm{~d}, \mathrm{SE}=0.25, \mathrm{n}=16$ ) followed by a cycle of short-trips of 1 to $4 \mathrm{~d}$ (mean $=1.31 \mathrm{~d}, \mathrm{SE}=0.04, \mathrm{n}=$ 226) lasting between 6 and $17 \mathrm{~d}$ (mean $=8.94 \mathrm{~d}, \mathrm{SE}=$ $0.55, \mathrm{n}=32$ ). No $5 \mathrm{~d}$ trips and only one $6 \mathrm{~d}$ trip were observed. Assuming foraging trips longer than $5 \mathrm{~d}$ are equivalent to long-trips observed in other Procellariiform species, then during our 20 d observation period, individual adults for which complete longtrips were observed spent on average 50.6\% (SE = $2.3 \%, \mathrm{n}=16$ ) of their foraging time on short-trips and $49.4 \%(\mathrm{SE}=2.3 \%, \mathrm{n}=16)$ on long-trips. The amount of time spent on short-trips or long-trips was not significantly different for these individuals (paired $t$-test: $t=0.274$, df $=15, \mathrm{p}=0.79$ ).

\section{Adult mass change}

Long-trips

On average adults were significantly heavier by $\sim 30$ to $40 \mathrm{~g}$ at the end of a long-trip (mean $=441.3 \mathrm{~g}, \mathrm{SE}=$ $7.04, \mathrm{n}=16$ ) than at the beginning (mean $=405.4 \mathrm{~g}$, $\mathrm{SE}=7.95, \mathrm{n}=16$ ) of the same long-trip (paired $t$-test: $t=$ -3.31 , df $=15, \mathrm{p}=0.005$ ) and gained $\sim 4 \mathrm{~g} \mathrm{~d}^{-1}$ (mean $=$ $3.75 \mathrm{~g} \mathrm{~d}^{-1}, \mathrm{SE}=1.20, \mathrm{n}=16$ ) while on long-trips. This result contrasts significantly with per day mass changes of the same adults during short-trips, where on average these adults lost $\sim 3 \mathrm{~g} \mathrm{~d}^{-1}$ (mean $=-2.88 \mathrm{~g}$ $\mathrm{d}^{-1}, \mathrm{SE}=1.88, \mathrm{n}=16$; paired $t$-test: $t=2.96, \mathrm{df}=15, \mathrm{p}=$ 0.006). Given that adults spend approximately equal time on long- and short-trip cycles, this implies that they lose approximately the same amount of weight during short-trips that they have gained during the previous long-trip.

Because adult mass measurements included food loads, some of the increase in adult weight during long-trips may be due to the food load on the first return visit after a long-trip being greater than for the last short-trip before departure. A direct test for this using relative meal mass calculated from chick weight changes as an independent measure of food load shows that the last meal before departure is, on average, the same size as the first meal supplied at return from a long-trip (mean change in chick mass prior to long-trip $=14.16 \mathrm{~g}, \mathrm{SE}=3.83, \mathrm{n}=16$; mean change in chick mass post long-trip $=12.46 \mathrm{~g}, \mathrm{SE}=3.19, \mathrm{n}=16$, paired $t$-test: $t=-0.357, \mathrm{df}=15, \mathrm{p}=0.73$ ). Therefore differences in adult weight before and after long-trips cannot be attributed solely to differences in food load 
returned to the chick. Importantly, this result also means that the yield to the chick in $\mathrm{g} \mathrm{d}^{-1}$ spent foraging is much lower after long-trips than short-trips, implying that adults do not undertake long-trips specifically for the benefit of chicks.

The length of each long-trip was negatively correlated with an individual's weight at the end of the proceeding short-trip cycle $\left(F_{1,14}=16.55\right.$, adjusted $\mathrm{r}^{2}=$ 0.51, $\mathrm{p}=0.001$, Fig. 2a). Therefore adult mass gain during a long-trip was directly related to both the length of the long-trip $\left(F_{1,14}=18.42\right.$, adjusted $r^{2}=0.57$, $\mathrm{p}=0.001$, Fig. $2 \mathrm{~b}$ ) and to the individual's weight at
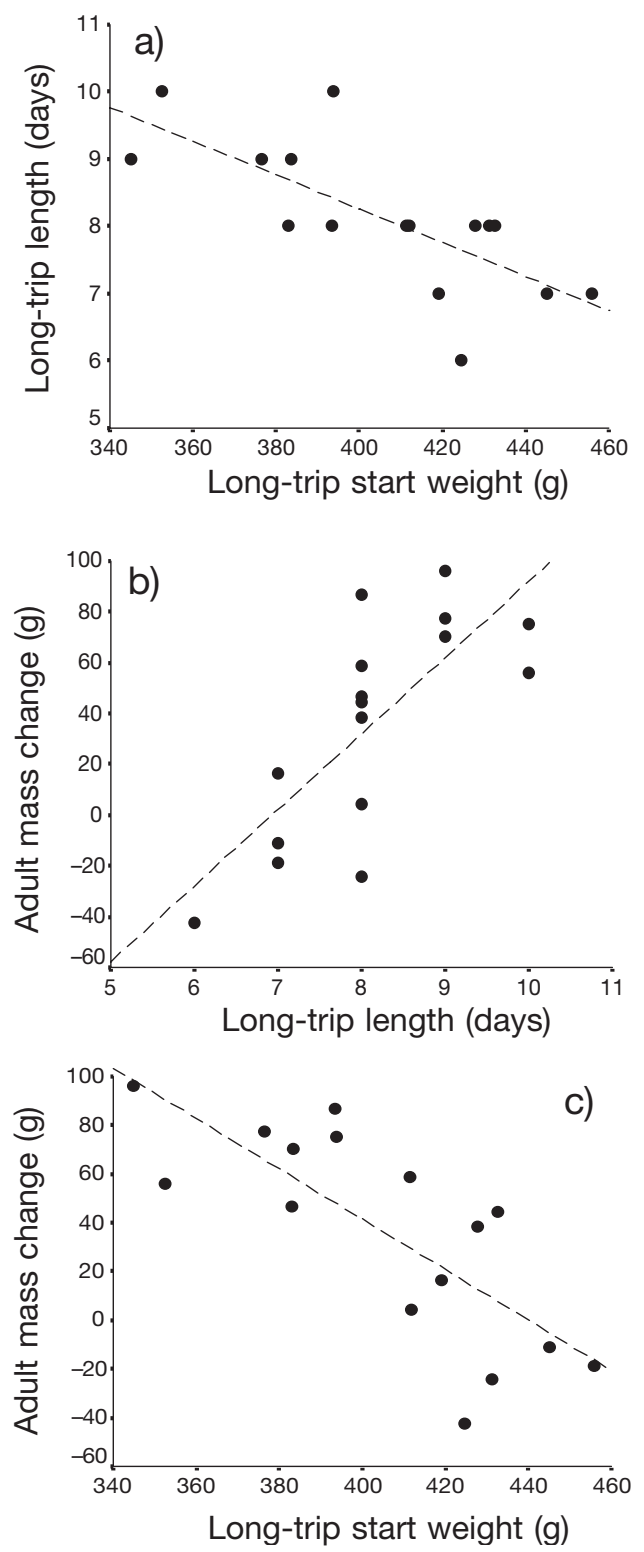

Fig. 2. Puffinus pacificus. Relationships between: (a) long-trip length and long-trip start weight, (b) long-trip length and adult mass change, and (c) long-trip start weight and adult mass change during February 2001 at Heron Island the end of the preceding short-trip cycle $\left(F_{1,14}=19.13\right.$, adjusted $r^{2}=0.55, p=0.001$, Fig. 2c). Only long-trips over $7 \mathrm{~d}$ produced positive adult weight gains. Conversely, an individual's weight at the start of the next short-trip cycle was not related to the length of the preceding long-trip $\left(F_{1,14}=1.67\right.$, adjusted $r^{2}=0.043$, $\mathrm{p}=0.22$ ).

\section{Short-trips}

As indicated previously, where complete long-trip cycles were observed the same adults lost on average $\sim 3 \mathrm{~g} \mathrm{~d}^{-1}$ during short-trips. Similarly, adults observed undertaking complete short-trip cycles were significantly lighter by the end of their short-trip cycle (mean $=405.3 \mathrm{~g}, \mathrm{SE}=5.6, \mathrm{n}=16$ ) than at the beginning (mean $=439.4 \mathrm{~g}, \mathrm{SE}=8.55, \mathrm{n}=16)$ of the same shorttrip cycle (paired $t$-test: $t=3.66$, df $=15, \mathrm{p}=0.002$ ) a decrease of $\sim 30$ to $40 \mathrm{~g}$. These same birds lost on average $\sim 5 \mathrm{~g} \mathrm{~d}^{-1}$ during short-trip cycles (mean $=5.63 \mathrm{~g} \mathrm{~d}^{-1}$, $\mathrm{SE}=1.14, \mathrm{n}=16)$. That adult weight declines during a short-trip cycle is further supported by a weak but significant negative relationship between adult mass and short-trip cycle day $\left(F_{1,109}=4.58\right.$, adjusted $\mathrm{r}^{2}=0.032$, $\mathrm{p}=0.035)$.

Unlike long-trips, short-trip cycle length was not related to adult weight at the start of the short-trip cycle $\left(F_{1,14}=0.50\right.$, adjusted $\left.\mathrm{r}^{2}=-0.034, \mathrm{p}=0.49\right)$. Birds that began short-trip cycles heavier did not remain on short-trip cycles longer. Nor was short-trip cycle end weight related to the length of the shorttrip cycle $\left(F_{1,14}=0.48\right.$, adjusted $\left.\mathrm{r}^{2}=-0.036, \mathrm{p}=0.50\right)$. Short-trip start weight and short-trip end weight were also not related $\left(F_{1,14}=0.50\right.$, adjusted $\mathrm{r}^{2}=$ $-0.034, p=0.49$ ), birds that weighed less at the beginning of short-trips did not necessarily leave on the next long-trip at a lighter weight. When all samples are combined, adults ended short-trip cycles in a relatively narrow band of weights between 375 to $425 \mathrm{~g}$, while variation in long-trip end weight was slightly broader at 400 to $480 \mathrm{~g}$ (Fig. 3). However, the coefficients of variation from these 2 distributions (CV: short-trip end weight $=66.8$, short-trip start weight $=70.0$ ) were not significantly different $\left(F_{31,31}=1.12, \mathrm{p}>0.05, \mathrm{n}=32\right)$.

Because adult weights include food loads, some of the adult mass loss observed during short-trips could be explained if adults bring back decreasing quantities of food over the short-trip period. This is supported by a weak but significant tendency for relative meal size, as measured independently by chick weight changes, to decrease during a short-trip cycle. $\left(F_{1,70}=6.11\right.$, adjusted $\left.\mathrm{r}^{2}=-0.067, \mathrm{p}=0.016\right)$. However, this decrease in the amount of food reaching chicks may have 


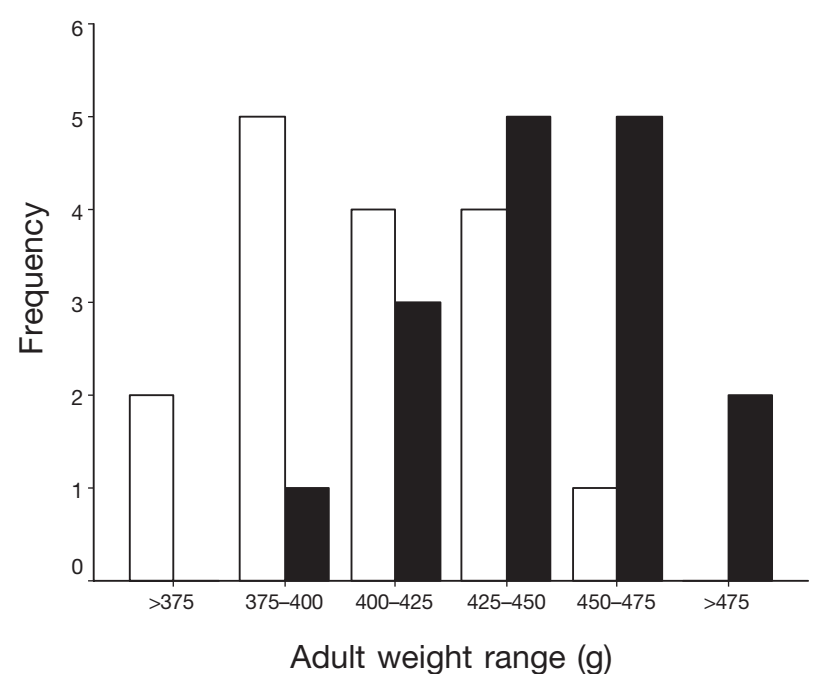

Fig. 3. Puffinus pacificus. Adult weight distribution at the beginning of long-trips (white bars) and at the end of the same long-trips (black bars)

another explanation. On average the adults undertaking these feeds lost $\sim 15 \mathrm{~g}$ (mean $=16.67 \mathrm{~g}, \mathrm{SE}=$ $5.84, \mathrm{n}=13$ ) on the first short-trip of a cycle but gained $\sim 8 \mathrm{~g}$ (mean $=8.99 \mathrm{~g}, \mathrm{SE}=7.15, \mathrm{n}=13$ ) on the last trip of the same short-trip cycle. These differences are significant (paired $t$-test: $t=-2.853, \mathrm{df}=12, \mathrm{p}=0.015$ ) with weight loss on the first short-trip day being significantly greater than zero. This suggests that rather than foraging success decreasing during a short-trip cycle, adults may tend to reallocate food from chick to self-provisioning by the end of a short-trip cycle depending on their own body condition. This conclusion is further supported by relative weight changes observed in adults during the course of their short-trip cycles. Adult weight declined relatively more during the first day of a short-trip cycle than during any other day, with adults appearing to attempt to maintain weight from Day 2 onwards (Fig. 4). Only mean weight loss on the first short-trip day was significantly greater than zero (Kruskal-Wallis, $\chi^{2}{ }_{5}=12.34, p=0.03$, Fig. 4).

\section{Chick condition and provisioning rates}

Change in chick mass (food assimilated) was significantly related to chick condition $24 \mathrm{~h}$ previous, suggesting that chicks in poorer condition were fed more at their next meal $\left(F_{1,82}=7.92\right.$, adjusted $\mathrm{r}^{2}=0.121, \mathrm{p}=$ 0.006, Fig. 5). This relationship had only weak explanatory power, suggesting that while chick condition may influence provisioning to some degree, it is unlikely that provisioning rates are decided solely by chick condition.

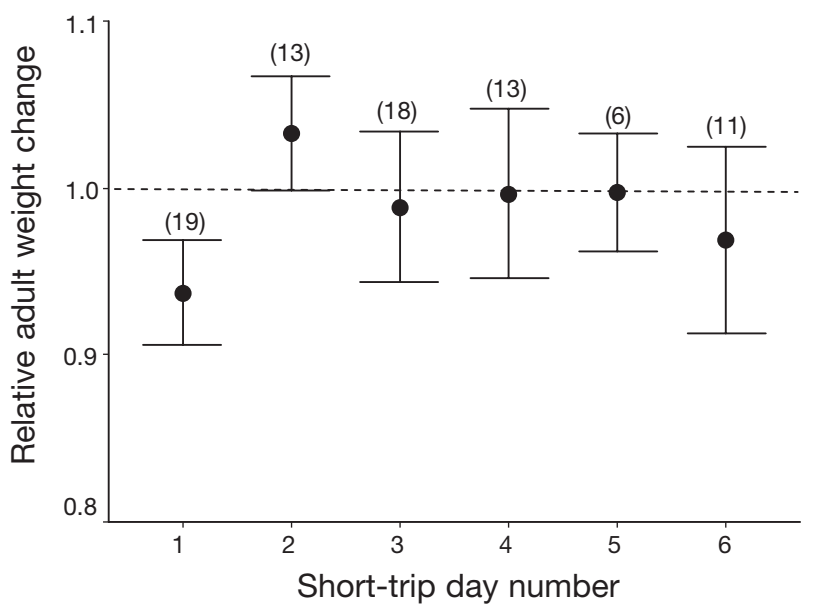

Fig. 4. Puffinus pacificus. Mean relative adult weight change ( $\pm 2 \mathrm{SE}$ ) during consecutive days of a short-trip cycle. Values $>1$ indicate weight increases, while values $<1$ indicate weight decreases compared to the previous day. A value equal to 1 indicates no change between days. Numbers in brackets indicate number of adults

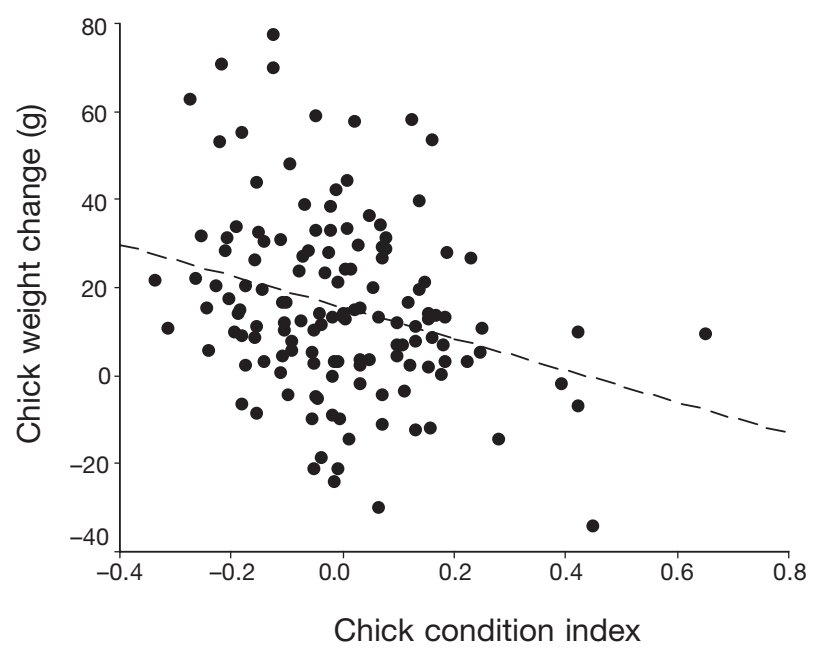

Fig. 5. Puffinus pacificus. Relationship between change in chick mass (food assimilated) and chick condition $24 \mathrm{~h}$ prior to the mass measurement

\section{Coordinated switching of adult foraging modes}

The majority of adults were last observed at their nest site completing a short-trip cycle one day prior to their mate returning from a long-trip (Fig. 6). While very few adults were observed completing short-trip cycles 2 to $3 \mathrm{~d}$ before or after their mate returned from a long-trip. This distribution was significantly different from that expected if mated individuals began longtrips randomly relative to each other (Likelihood ratio $\chi^{2}{ }_{4}=12.12, \mathrm{p}=0.017, \mathrm{n}=26$, Fig. 6), and strongly suggests that pairs may in some way co-ordinate longtrip changeovers. 


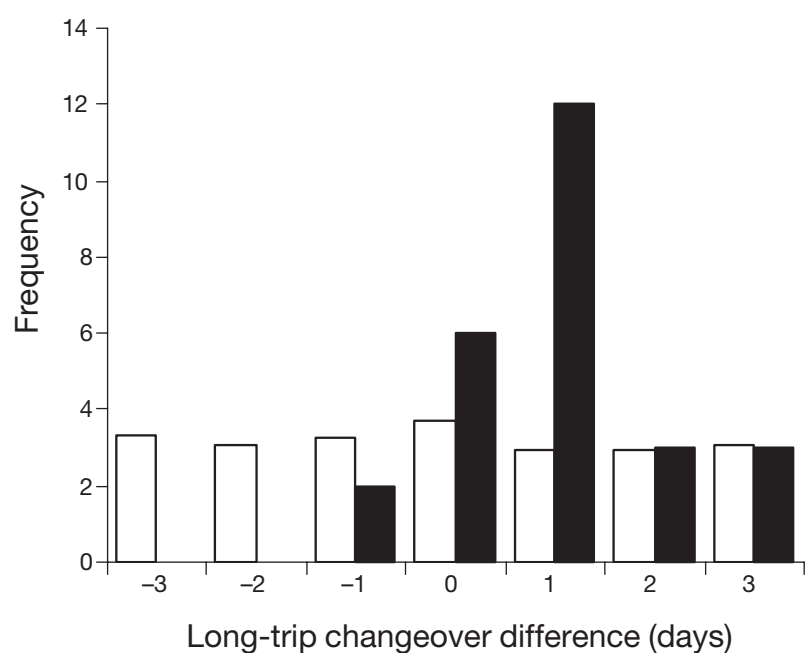

Fig. 6. Puffinus pacificus. Adult foraging trip changeover distribution. Observed (black bars) and expected (white bars) distribution of the number of days between when one adult starts a long-trip and its mate returns from the most temporally associated long-trip

\section{DISCUSSION}

\section{Dual foraging in wedge-tailed shearwaters}

In 2001, wedge-tailed shearwaters nesting in the southern GBR used a dual-foraging strategy with a clear dichotomy between short-trip cycles involving multiple trips of 1 to $4 \mathrm{~d}$ (mean = 1.31) and long-trips of between 6 and $10 \mathrm{~d}$ (mean =8.06). Adults spent approximately half of their foraging time on long-trips. They gained weight on long-trips, lost weight during shorttrip cycles and appeared to deplete body reserves by the approximate amount they had gained during the preceding long-trip. Overall, the mass-change and triplength relationships suggest that adult shearwaters use long-trips to build body reserves that they pass on to chicks by not self-provisioning adequately during the early stages of a short-trip cycle. After passing on these reserves they attempt to satisfy chick requirements while maintaining their own weight, but tend not to be able to maintain weight effectively. This implies that adults cannot consistently obtain sufficient food to provision both themselves and chicks during short-trip cycles. The inability of adults to maintain mass effectively during short-trip cycles maybe due, in part, to provisioning rates being determined by chick condition.

\section{Switching of adult foraging modes}

For wedge-tailed shearwaters breeding at Heron Island no relationship was observed between adult mass and the length of short-trip cycles. Variance in adult body mass appeared to decrease during shorttrip cycles, suggesting that adults may attempt to maintain body reserves above some specific mass, as has been observed for temperate species (Weimerskirch 1998, Weimerskirch \& Cherel 1998). However, unlike temperate species adults did not begin longtrips immediately after reaching this mass, nor were changeovers in foraging mode random among mated adults. Instead, changeovers appeared to be coordinated. Short-tripping adults were consistently observed completing short-trip cycles the day before, or on the same day that their mates returned from a longtrip. This means that adults either: (1) maintained the appearance of co-ordinated changeover by chance despite foraging independently, (2) have an inherent endogenous rhythm that remains in phase with their partner despite possible variations in long-trip length, (3) were able to predict the return of their mate with considerable accuracy, or (4) that changeovers are triggered by the return of one mate from a long-trip through contact either at the nest or, more probably, at sea. Which of these mechanisms is operating is unclear, but the latter of the 4 seems the most likely.

Our findings suggest that overall, the dual-foraging pattern observed for wedge-tailed shearwaters at Heron Island develops as a consequence of the average or median period of time adults spend on long-trips. Long-trip length was directly related to adult weight at the beginning of the same long-trip. Adults did not remain on long-trips for a preset period during which they attempted to maximise weight gain. Instead they appeared to remain on long-trips until they had either regained reserves lost during the previous short-trip cycle and/or their weight approached some specific level. This suggests that the overall foraging pattern observed was determined by the time it takes adults on long-trips to reach a specific body mass that they are attempting to achieve $(\sim 440 \mathrm{~g})$, possibly their mass at the beginning of the breeding season, or the maximum weight that allows for efficient aerodynamics during foraging. In temperate Procellariiformes long-trip length is believed to be optimised so as to maximise adult energy gains relative to expenditure, with median long-trip length being that at which mass gain and foraging efficiency peaks (Weimerskirch et al. 2003). If, for wedge-tailed shearwaters, foraging efficiency on longtrips decreases at body mass greater than $\sim 440 \mathrm{~g}$, then our findings are consistent with this model.

\section{'At-distance' foraging in wedge-tailed shearwaters}

In many temperate species, dual-foraging strategies such as we observed in wedge-tailed shearwaters have been unambiguously associated with use of distant, 
highly productive foraging areas in high-latitude regions (e.g. Catard et al. 2000, Klomp \& Schultz 2000). Furthermore, when near-colony resources can sustain both chick and adult requirements as in Hawaii, wedge-tailed shearwaters do not use a dual-foraging strategy (Baduini 2002). Combined, these results imply that wedge-tailed shearwaters of the southern GBR use dual-foraging to access 'at-distance' areas of highproductivity in the tropics within reach of GBR nesting sites to supplement food input to chicks beyond what is possible using only locally available resources.

Alternatively, if the energetic costs of short-trips are much greater than long-trips, then adults doing shorttrips in resource-poor environments for provisioning purposes may use a bimodal strategy to mitigate the energetic costs of these trips, without using 'at-distance' locations (as per Ropert-Coudert et al. 2004). That is, adults on long-trips may remain close to the colony and take prey solely for their own use, minimizing the energetic costs of travel in the process. This possibility remains untested. Major differences in the energetic costs associated with long- and short-trips have been documented (Weimerskirch et al. 2003). However, the increased efficiency of long-trips per se has not been established. Higher energy gains associated with longtrips are yet to be separated from the use of 'atdistance' locations having foraging conditions and prey types that may improve efficiency (Weimerskirch et al. 2003). Also, the $8 \mathrm{~d}$ on, $8 \mathrm{~d}$ off cycle we observe does not appear to be an optimal risk avoidance strategy for birds constantly foraging in a resource-poor environment where $1 \mathrm{~d}$ trips are unable to support both chick and adult requirements. From a theoretical perspective, a strategy approximating $1 \mathrm{~d}$ on, $1 \mathrm{~d}$ off, would better minimise large fluctuations in both chick and adult body mass while still entailing similar foraging effort and number of return trips.

Comparing our results to Baduini's (2002), it seems that foraging strategies among wedge-tailed shearwater populations vary spatially relative to near-colony resource availability. Similar results have been obtained for black-browed albatross, a southern ocean temperate species (Waugh et al. 2000). Changes in foraging strategy associated with temporal variation in resources have also been observed. Cory's shearwaters in the north-eastern Atlantic use dual-foraging only in years of low resource abundance (Granadeiro et al. 1998). Such variations within a single population suggest the use of dual-foraging may be facultative rather than a fixed colony-specific trait. However, the exact dual-foraging pattern appropriate for different colonies could be influenced by the distribution of 'atdistance' foraging areas and become colony specific through the process of selection. We believe this possibility requires further critical investigation.

\section{CONCLUSION}

In conclusion, when near-colony resources are such that 1-d foraging trips are unable to support both chick and adult energy requirements, wedge-tailed shearwaters adopt a dual-foraging strategy similar to that observed in temperate species. Therefore, dual foraging is a general Procellariiform life-history strategy used to address similar ecological constraints in both temperate and tropical systems. Whether dualforaging is linked to the use of 'at-distance' resources, or whether it enables shearwaters to breed using poor quality local resources requires further testing. However, if the former is true, the conservation significance of such tropical foraging refuges cannot be overstated. An influx of warm sea-surface water to the Southern GBR in 2002 coincided with a complete reproductive failure of wedge-tailed shearwaters (Smithers et al. 2003). While the available data suggests that adult condition was not directly affected (Smithers et al. 2003), this collapse demonstrates the relative sensitivity of wedge-tailed shearwaters and possibly other seabirds to sea-surface temperature variation and global climate change. The breeding success of these species on a regional scale may be totally dependent on the continued stability of a small number of these highly productive areas.

Acknowledgements. We thank the management and staff of the Heron Island Research Station for help during the field components of this project. This research was funded by a James Cook University Merit Research Grant (MRG00/0026), and was authorised under QNPWS Permits C6/000175/00/SAA, C6/000195/01/SAA and James Cook University-Ethics Approval A627_00.

\section{LITERATURE CITED}

Ashmole NP (1971) Seabird ecology and the marine environment. In: Farner DS, King JR (eds) Avian biology, Vol 1. Academic Press, New York, p 223-286

Baduini CL (2002) Parental provisioning patterns of wedgetailed shearwater chicks and their relation to chick body condition. Condor 104:823-831

Catard A, Weimerskirch H, Cherel Y (2000) Exploitation of distant Antarctic waters and close shelf-break waters by white-chinned petrels rearing chicks. Mar Ecol Prog Ser 194:249-261

Chaurand T, Weimerskirch H (1994) The regular alternation of short and long foraging trips in the Blue petrel Halobaena caerulea: a previously undescribed strategy of food provisioning in a pelagic seabird. J Anim Ecol 63:275-282

Fernandez P, Anderson DJ, Sievert PR, Huyvaert KP (2001) Foraging destinations of three low-latitude albatross (Phoebastria) species. J Zool 254:391-404

Granadeiro J, Nunes PM, Silva MC, Furness RW (1998) Flexible foraging strategy of Cory's shearwater, Calonectris diomedia, during the chick-rearing period. Anim Behav 56:1169-1176

Hamer KC, Thompson DR (1997) Provisioning and growth 
rates of nestling Fulmars Fulmarus glacialis: stochastic variation or regulation. Ibis 139:31-39

Hamer KC, Lynnes AS, Hill JK (1999) Parent-offspring interactions in food provisioning in Manx shearwaters: implications for nestling obesity. Anim Behav 57:627-631

Hyrenbach KD, Fernandez P, Anderson DJ (2002) Oceanic habitats of two sympatric North Pacific albatross during the breeding season. Mar Ecol Prog Ser 233:283-301

Klomp NI, Schultz MA (2000) Short-tailed shearwaters breeding in Australia forage in Antarctic waters. Mar Ecol Prog Ser 194:307-310

Ropert-Coudert Y, Wilson RP, Daunt F, Kato A (2004) Patterns of energy acquisition by a central place forager: benefits of alternating short and long foraging trips. Behav Ecol 15: 824-830

Smithers BV, Peck DR, Krockenberger AK, Congdon BC (2003) Elevated sea-surface temperature, reduced provisioning and reproductive failure of wedge-tailed shearwaters (Puffinus pacificus) in the southern Great Barrier Reef, Australia. Mar Freshw Res 54:973-977

Editorial responsibility: Otto Kinne (Editor-in-Chief), Oldendorf/Luhe, Germany
Waugh SM, Weimerskirch H, Cherel Y, Prince PA (2000) Contrasting strategies of provisioning and chick growth in two sympatrically breeding albatrosses at Campbell Island, New Zealand. Condor 102:804-813

Weimerskirch H (1998) How can a pelagic seabird provision its chick when relaying on a distant food resource? Cyclic attendance at the colony, foraging decision and body condition in sooty shearwaters. J Anim Ecol 67: 99-109

Weimerskirch H, Cherel Y (1998) Feeding ecology of shorttailed shearwaters: breeding in Tasmania and foraging in the Antarctic? Mar Ecol Prog Ser 167:261-274

Weimerskirch H, Prince PA, Zimmerman L (2000) Chick provisioning by the yellow-nosed albatross Diomedea chlororhynchos: response of foraging effort to experimentally increased costs and demands. Ibis 142:103-110

Weimerskirch H, Ancel A, Caloin M, Zahariev A, Spagiari J, Kersten M, Chastel O (2003) Foraging efficiency and adjustment of energy expenditure in a pelagic seabird provisioning its chick. J Anim Ecol: 72:500-508

Submitted: November 16, 2004; Accepted: May 3, 2005 Proofs received from author(s): September 21, 2005 